\title{
Cinacalcet - Clinical and Laboratory Effectiveness, Concomitant Treatment Patterns and Treatment Cost: Could We Do Better and How?
}

\author{
Jana Smržováa Tomáš Urbánek ${ }^{b}$ \\ a Dialysis and Nephrology Center, University Hospital, Brno, and INMED, Svitavy, and ${ }^{\mathrm{b}}$ Institute of Psychology, \\ Academy of Sciences of the Czech Republic, Brno, Czech Republic
}

\section{Key Words}

Cinacalcet $\cdot$ Itching $\cdot$ Phosphate binders .

Hyperparathyroidism, secondary $\cdot$ Vitamin D .

Dialysis, cost of $\cdot$ Chronic kidney failure

\begin{abstract}
Background: The cost and effectiveness patterns in the treatment of secondary hyperparathyroidism (SHPT) in dialysis patients in the Czech Republic are unknown. Methods: $52 \mathrm{di}-$ alysis patients from 17 centers were followed up in a multicenter prospective study of laboratory and clinical (hospitalization rate, clinical complaints questionnaire) responses to 12-month cinacalcet treatment. Treatment patterns and cost (including phosphate binders, vitamin D, and cinacalcet) were evaluated. Results: The mean s-Ca dropped significantly from $2.36 \pm 0.24$ to $2.21 \pm 0.20 \mathrm{mmol} / \mathrm{l}, \mathrm{s}-\mathrm{P}$ from $2.45 \pm$ 0.54 to $2.01 \pm 0.53 \mathrm{mmol} / \mathrm{l}, \mathrm{Ca} \times \mathrm{P}$ from $5.79 \pm 1.25$ to $4.42 \pm$ $1.13 \mathrm{mmol}^{2} / \mathrm{I}^{2}$, and iPTH dropped from $919.0 \pm 465.6$ to 372.1 $\pm 294.6 \mathrm{pg} / \mathrm{ml}$. The mean cinacalcet dose reached $44.1 \pm$ $23.0 \mathrm{mg} /$ day after 12 months. Itching intensity decreased significantly. No change in hospitalization rate was observed. The direct cost of daily SHPT treatment rose significantly from EUR $8.77 \pm 9.59$ to $20.62 \pm 9.22$. Conclusions: Cinacalcet decreased elevated s-Ca, s-P, Ca $\times$ P, and iPTH, alleviated itching, and significantly raised the SHPT treatment cost. A minority of patients reached K/DOQI targets, especially due to poor phosphate control caused by insufficient phosphate binder treatment, cinacalcet underdosing, and advanced SHPT.
\end{abstract}

Copyright $\odot 2010$ S. Karger AG, Basel

\section{KARGER}

Fax +41613061234 E-Mail karger@karger.ch www.karger.com
(C) 2010 S. Karger AG, Base

$1420-4096 / 10 / 0335-0333 \$ 26.00 / 0$

Accessible online at: www.karger.com/kbr

\section{Introduction}

Chronic kidney disease patients often develop secondary hyperparathyroidism (SHPT) due to altered calcium, phosphate, and vitamin D metabolism $[1,2]$. The calcium-sensing receptor $(\mathrm{CaR})$ on parathyroid gland cells plays a key role in the PTH production and secretion regulation as it induces $\mathrm{PTH}$ production and secretion in hypocalcemia. On the other hand, the production and secretion of $\mathrm{PTH}$ are lowered by active vitamin $\mathrm{D}$, which acts on the nucleic vitamin $\mathrm{D}$ receptor. If $\mathrm{PTH}$ production is stimulated for a long time, parathyroid cell proliferation occurs, leading to diffuse or (later) to nodular hyperplasia. In such a situation, the expression of $\mathrm{CaR}$ and vitamin $\mathrm{D}$ on parathyroid cells diminishes, thus making the PTH production control by calcemia or vitamin D less effective.

The treatment of SHPT must be complex. The cornerstone of treatment is good hyperphosphatemia control using (1) a sufficient dose and frequency of dialysis, (2) low-phosphorus diet, and (3) phosphate binders in sufficient doses, administered the right way.

Two types of drugs are able to act directly against SHPT - the group of active vitamin D and its analogs or precursors acting via the vitamin $\mathrm{D}$ receptor, and calcimimetics that exert their action via CaR. Vitamin D sterols often lead to hypercalcemia and/or hyperphosphatemia and induce soft tissue calcifications, which limit their use [3-6]. Cinacalcet, the only clinically available

Jana Smržová, MD, PhD

Vychodilova 16

CZ-616 00 Brno (Czech Republic)

Tel. +420 777305 668, Fax +420 530312 100, E-Mail jsmrzova@gmail.com 
calcimimetic, is an allosteric modulator of $\mathrm{CaR}$ that sensitizes the receptor to extracellular calcium and thus suppresses PTH secretion [7]. The drop in iPTH is accompanied by a drop in calcemia (s-Ca), phosphatemia (s-P), and the calcium-phosphorus product $(\mathrm{Ca} \times \mathrm{P})$ [8]. As for the Kidney Disease Outcomes Quality Initiative (K/ DOQI) targets for s-Ca, s-P, Ca $\times$ P, and iPTH [9], cinacalcet raises the proportion of patients meeting them $[10$, 11]. The prevention or regression of hypertrophy of the parathyroid glands with the use of cinacalcet have also been described $[12,13]$.

Cinacalcet became available on the Czech market in 2005. Due to prescription limitations enforced by medical care insurance companies as well as its high price, in most dialysis centers of the Czech Republic only a small proportion of patients is treated. Therefore, the clinical experience in using the drug is still rather limited. To address this issue, we conducted the Mimpara Management in Moravia (MMM) study presented below (Moravia is part of the Czech Republic where the study was carried out).

\section{Subjects and Methods}

\section{Study Design}

The MMM was a prospective multicenter 1-year follow-up of dialysis patients who started treatment with cinacalcet for SHPT.

The aims of the study were as follows: (1) to describe the profile of patients who started treatment with cinacalcet in the Czech Republic; (2) to assess treatment with cinacalcet in terms of dose, side effects, and concomitant treatment of SHPT; (3) to evaluate the effectiveness of treatment in terms of clinical and laboratory data; (4) to assess the percentage of patients meeting the K/DOQI criteria for calcium-phosphorus metabolism during and before treatment with cinacalcet; (5) to compare the hospitalization rate during and before treatment with cinacalcet, and (6) to compare the direct cost of medical SHPT therapy during and before treatment with cinacalcet.

\section{Population}

The inclusion criteria included moderate to severe SHPT (with iPTH of $>476 \mathrm{pg} / \mathrm{ml}$, e.g. $50 \mathrm{pmol} / \mathrm{l})$, dialysis treatment, age over 18 years, and consent to cinacalcet treatment and participation in the study. Noncompliance with treatment occurring during the follow-up did not represent an exclusion criterion.

\section{Data Collection}

Patients were enrolled from 17 of 27 centers in the region (the participation in the study being voluntary) between November 2006 and April 2007, and the data were collected during the 12-month follow-up. The data from a 6-month period preceding cinacalcet treatment were collected retrospectively. No treatment or examination protocols were provided and no clinic visits were required other than those regularly scheduled. Therefore, the study observed the current clinical practice. The following variables were collected by the patients' nephrologists at baseline: age, gender, etiology of chronic kidney disease, medical history including kidney transplantation and parathyroidectomy, comorbidities, dialysis start date, dialysis modality, dialysis frequency and duration, concurrent medication. Laboratory findings, drugs prescribed, adverse drug reactions, and need for hospitalization were registered throughout the study.

Biochemical and hematological tests (calcemia, phosphatemia, iPTH level, albuminemia, magnesemia, CRP, hemoglobin concentration, vitamin $\mathrm{D}$, calcidiol and calcitriol blood level, blood $\mathrm{pH}, \mathrm{pCO}_{2}, \mathrm{HCO}_{3}^{-}$, alkaline phosphatase) were carried out in local laboratories. Blood samples were taken before the start of the dialysis session. Kt/V was calculated by the Daugirdas equation of the 2nd generation, one-compartment model. Complementary examinations (skeleton X-ray, sonography, CT, and scintigraphy of parathyroid glands) were done in local facilities and were recommended by the patients' nephrologist. Only examinations made during the study or within 6 months prior to the start of the study were considered for evaluation.

The intensity of clinical complaints was evaluated on an analog scale from 0 (no complaint) to 10 (maximum intensity) with a simple questionnaire at the start of the cinacalcet treatment (month 0 ) as well as 6 and 12 months later. The questionnaire assessed the intensity of itching, fatigue, digestive problems, bone pain, and muscle weakness.

To assess the effectiveness of cinacalcet treatment, we used the K/DOQI criteria from 2003 (s-Ca 2.10-2.38 mmol/l, s-P 1.13-1.78 $\mathrm{mmol} / \mathrm{l}, \mathrm{Ca} \times \mathrm{P}<4.44 \mathrm{mmol}^{2} / \mathrm{l}^{2}$ and iPTH $150-300 \mathrm{pg} / \mathrm{ml}$ ) [9] as the study was designed in 2006 when the K/DOQI targets were used most widely in the Czech Republic.

As for the assessment of treatment cost, only direct expenses were included in the calculation (the cost of cinacalcet, vitamin D or its analogs, phosphate binders). The indirect costs of the SHPT treatment (e.g. costs of examinations and laboratory tests, hospitalization, parathyroidectomy, other treatments including the treatment of complications) were not included in the calculation. The prices of drugs valid in July 2007 were considered for the calculation.

\section{Statistical Analysis}

Statistical analysis was performed with the statistical software SPSS 15.0 (SPSS for Windows, Rel. 15.0.5. (2006); SPSS Inc., Chicago, Ill., USA). Summary statistics are expressed as frequencies for categorical variables, mean values with SD for normally distributed variables. The repeated ANOVA measures, paired Student's t test or an unpaired t test where appropriate were used for comparisons of data relating to the time before and during the treatment. The comparisons of treatment effect between subgroups were done using paired Student's t test or unpaired t test, Wilcoxon sign test, Kruskal-Wallis test, and $\chi^{2}$ test. For all comparisons, $\mathrm{p}<0.05$ was considered statistically significant.

Missing laboratory data were calculated by linear interpolation for the use of ANOVA. This way, 3.27\% of s-Ca values, 3.62\% of s-P and $\mathrm{Ca} \times \mathrm{P}$ values, and $8.98 \%$ of iPTH values were calculated. 


\section{Results}

\section{Profile of Patients Who Started the Cinacalcet} Treatment

52 patients from 17 centers entered the study. Their baseline demographic and laboratory data are listed in table 1.

\section{Cinacalcet Dose, Side Effects of Treatment, and}

\section{Concomitant Treatment of SHPT}

The cinacalcet dose was raised linearly until month 4 and was not changed afterwards. The dose in month 12 was $44.1 \pm 23.0 \mathrm{mg} /$ day. The most frequently used doses were 30 and $60 \mathrm{mg} /$ day.

Four patients $(7.7 \%)$ discontinued treatment, the reasons being: (1) hypocalcemia and elevation of transaminases (month 1); (2) nausea, vomiting, abdominal pain and tiredness (month 4); (3) heart failure (month 5), and (4) dyspepsia (month 8). In 2 patients (3.8\%), the drug was discontinued transiently, in 1 for severe hypocalcemia and drop in iPTH (month 3), in the other patient for health status deterioration stemming from inadequate peritoneal dialysis (month 3 ). The following events were noted during the treatment: hypocalcemia without cramps (1 patient); hypocalcemia and cramps (1 patient); dyspepsia (1 patient); newly reported extra-osseal calcifications ( 1 patient), and collapses and worsening hypertension (1 patient). One patient with chronic sepsis died during the study because of bronchopneumonia.

Use of vitamin D sterols was lowered immediately after the start of cinacalcet treatment (from 67.3 to $44.8 \%$ of patients). Nevertheless, most of the patients resumed taking the drug and thus $63.2 \%$ of patients were on vitamin D sterols at the end of study. Otherwise, while the changes in mean doses were not significant, the shift from pulse towards continuous vitamin D administration was (table 2).

$87.8 \%$ of patients were prescribed phosphate binders at baseline; most received sevelamer (61.1\%) and/or calcium carbonate (49.1\%). Other available binders were lanthanum carbonate and aluminium-based binders. The doses of phosphate binders did not change significantly. However, a wider use of combination therapy (2 different phosphate binders) was noted (18.4 vs. $29.3 \%)$. Lanthanum carbonate was used more often, but only a few patients received it (table 3 ).

Calcium concentrations in the dialysate were $1.46 \pm$ 0.21 and $1.51 \pm 0.21 \mathrm{mmol} / \mathrm{l}$, respectively, but the difference was not significant (Wilks' $\lambda=0.639, F=1,638$, d.f. $=10, p=0.145$ ).
Table 1. Patient demographics and baseline laboratory values before the start of cinacalcet treatment

\begin{tabular}{|c|c|}
\hline Variable & Total $(\mathrm{n}=52)$ \\
\hline \multicolumn{2}{|l|}{ Demographics } \\
\hline Mean age $\pm S D$, years & $55.5 \pm 12.1$ \\
\hline Male gender, $\%$ & 53.8 \\
\hline Previous kidney transplant, \% & 13.5 \\
\hline Dialysis vintage $\pm \mathrm{SD}$, months & $59.3 \pm 55.6$ \\
\hline \multicolumn{2}{|l|}{ Type of dialysis } \\
\hline Peritoneal dialysis, $\%$ & 3.8 \\
\hline Hemodialysis, \% & 96.2 \\
\hline Low-flux HD, \% & 38.5 \\
\hline High-flux HD, \% & 25.0 \\
\hline Hemodialfiltration, \% & 23.1 \\
\hline Low-flux HD + hemodialfiltration, $\%$ & 5.8 \\
\hline High-flux HD + hemodialfiltration, \% & 3.8 \\
\hline Number of dialysis sessions/week (range) & $2.98(2-4)$ \\
\hline Dialysis session duration, h (range) & $4.2(3-5)$ \\
\hline Weekly dialysis duration, $\mathrm{h}$ (range) & $12.5(8-15)$ \\
\hline $\mathrm{Kt} / \mathrm{V}$, mean $\pm \mathrm{SD}$ & $1.42 \pm 0.31$ \\
\hline $\operatorname{URR}(\%)$, mean $\pm \mathrm{SD}$ & $69.6 \pm 6.6$ \\
\hline \multicolumn{2}{|l|}{ Calcifications } \\
\hline Vascular calcifications, \% & 42.3 \\
\hline Non-vascular calcifications, $\%$ & 26.9 \\
\hline Valvular, \% & 19.2 \\
\hline Periarticular, \% & 19.2 \\
\hline Pulmonary, \% & 1.9 \\
\hline Corneal, \% & 1.9 \\
\hline Other soft tissue, $\%$ & 5.8 \\
\hline \multicolumn{2}{|l|}{ Comorbidities } \\
\hline Diabetes mellitus, \% & 21.1 \\
\hline Arterial hypertension, \% & 80.8 \\
\hline Left ventricle hypertrophy, \% & 42.3 \\
\hline Peripheral artery disease, $\%$ & 23.1 \\
\hline Chronic heart failure, $\%$ & 21.1 \\
\hline Myocardial infarction, \% & 15.3 \\
\hline Cerebrovascular disease, $\%$ & 15.3 \\
\hline Arrhythmias, \% & 13.5 \\
\hline Other cardiovascular comorbidities, \% & 9.6 \\
\hline \multicolumn{2}{|l|}{ Parathyroid gland examination } \\
\hline Ultrasonography, \% & 61.5 \\
\hline Scintigraphy, \% & 26.9 \\
\hline Computed tomography, \% & 9.6 \\
\hline No examination performed, $\%$ & 38.5 \\
\hline Enlarged parathyroid glands, \% & 42.3 \\
\hline Normal finding on parathyroid glands, $\%$ & 19.2 \\
\hline Previous surgical parathyroidectomy, \% & 5.8 \\
\hline Previous chemical parathyroidectomy, \% & 3.8 \\
\hline
\end{tabular}

Kidney Blood Press Res 2010;33:333-342 


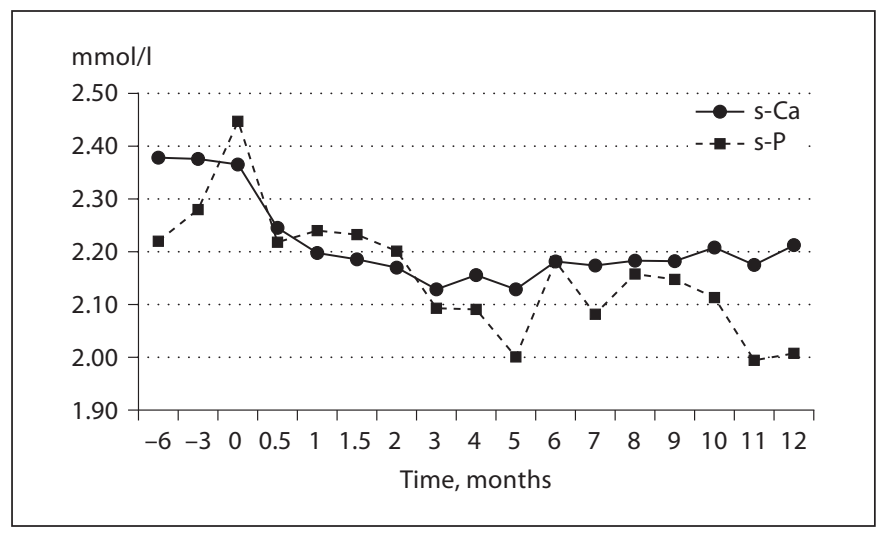

Fig. 1. Calcemia and phosphatemia during the cinacalcet treatment. The administration of cinacalcet started in month 0 . The increase in borderline significance of s-P $(\lambda=0.885, F=2.861$, d.f. $=2, p=0.068)$ and no changes in $s-\mathrm{Ca}(\lambda=0.955, \mathrm{~F}=1.060$, d.f. $=2, p=0.355)$ before the start of the cinacalcet treatment are shown; as are the significant quadratic and cubic decreasing trend for $\mathrm{s}-\mathrm{Ca}(\lambda=0.314, \mathrm{~F}=4.205$, d.f. $=14, \mathrm{p}=0.001)$ and significant linear and cubic decreasing trend for $\mathrm{s}-\mathrm{P}(\lambda=0.253, \mathrm{~F}=7.700$, d.f. $=14, \mathrm{p}=0.000)$ during treatment.

\section{Clinical and Laboratory Impact of the Treatment}

As shown in figures 1 and 2, we observed a significant drop in s-Ca, s-P, Ca $\times$ P, and iPTH levels during the cinacalcet treatment. Mean s-Ca dropped from 2.36 \pm 0.24 to $2.21 \pm 0.20 \mathrm{mmol} / \mathrm{l}, \mathrm{s}-\mathrm{P}$ from $2.45 \pm 0.54$ to $2.01 \pm 0.53 \mathrm{mmol} / \mathrm{l}, \mathrm{Ca} \times \mathrm{P}$ from $5.79 \pm 1.25$ to $4.42 \pm$ $1.13 \mathrm{mmol}^{2} / \mathrm{l}^{2}$, and iPTH from $919.0 \pm 465.6$ to $372.1 \pm$ $294.6 \mathrm{pg} / \mathrm{ml}$ between months 0 and 12 . The changes were significant except for iPTH where the decrease was of borderline significance $(\mathrm{p}=0.055)$. In addition, the multivariate test demonstrated a significant raising trend in s-P and $\mathrm{Ca} \times \mathrm{P}$ during the 6 months preceding the start of the cinacalcet treatment, whereas the changes in s-Ca and $\mathrm{iPTH}$ were not significant during this period.

As for the clinical complaints, cinacalcet manifested a more pronounced beneficial effect over the first 6 months than it did over the following 6 months. Over the first 6 months, the intensity of itching, fatigue, bone pain, and muscle weakness, but not that of digestive disorders, dropped significantly. It returned to previous values for fatigue, bone pain, and muscle weakness in month 12 . Only the alleviation of itching remained stable over the 12 months. The total score of clinical complaints dropped from $13.74 \pm 10.86$ to $10.09 \pm 8.53$ from months 0 to 6 $(\mathrm{p}=0.000)$ and reached the value of $11.05 \pm 8.53$ (n.s.) in month 12. The results are listed in table 4 .

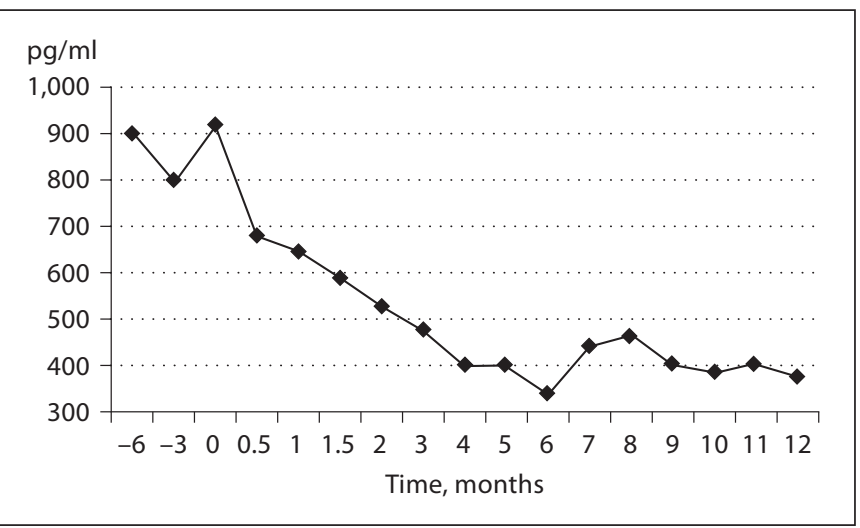

Fig. 2. iPTH levels during the cinacalcet treatment; the administration of cinacalcet started in month 0 . Significant variations in iPTH levels $(\lambda=0.855, \mathrm{~F}=3.607$, d.f. $=2, \mathrm{p}=0.030)$ before the start of the cinacalcet treatment ending up in a quadratic type of curve; linear and quadratic decreasing trend of borderline significance $(\lambda=0.102, \mathrm{~F}=3.784$, d.f. $=14, \mathrm{p}=0.055)$ during the treatment.

Percentage of Patients Meeting the K/DOQI Criteria for Calcium-Phosphorus Metabolism

The percentage of patients meeting the targets at baseline and in month 12 increased significantly for s-Ca (40.8 and 65.9\%; $\mathrm{p}=0.002), \mathrm{Ca} \times \mathrm{P}(14.3$ and 51.2\%; $\mathrm{p}=$ $0.000)$, and for iPTH (6.4 and 39\%; $\mathrm{p}=0.000)$. The increase for s-P was not significant (6.1 and 17.1\%; $\mathrm{p}=$ $0.160)$. The data are presented in detail in figure 3 . The percentage of patients meeting a combination of 2,3 or 4 K/DOQI targets increased during treatment (fig. 4), but only $7.3 \%$ met all $4 \mathrm{~K} / \mathrm{DOQI}$ targets in month 12 , whereas no patient did so at baseline.

\section{Comparison of Hospitalization Rates during and before Cinacalcet Treatment}

There was no difference in the hospitalization rate before treatment and during the first 6 months of treatment (0.51 hospitalizations/patient/6 months, e.g. 85.0 hospitalizations/1,000 patient months vs. 0.40 hospitalizations/patient/6 months, e.g. 66.7 hospitalizations/1,000 patient months; $\mathrm{p}=0.553)$. The same applies to the rates before and during the following 6 months of treatment (0.52 hospitalizations/patient/6 months, e.g. 87.3 hospitalizations $/ 1,000$ patient months; $\mathrm{p}=0.864$ ).

\section{Comparison of Direct Cost of Medical SHPT Therapy} during and before Cinacalcet Treatment

The total direct cost of mineral and bone disorder treatment during chronic kidney disease including the 
Table 2. Use of vitamin D sterols

\begin{tabular}{|c|c|c|c|c|c|}
\hline Drug & $\begin{array}{l}\text { Treated patients } \\
\text { at baseline, } \%\end{array}$ & $\begin{array}{l}\text { Mean dose at } \\
\text { baseline } \\
\mu \mathrm{g} / \text { week }\end{array}$ & $\begin{array}{l}\text { Treated patients after } \\
12 \text { months on cinacalcet } \\
\%\end{array}$ & $\begin{array}{l}\text { Mean dose after } \\
12 \text { months on } \\
\text { cinacalcet, } \mu \mathrm{g} / \text { week }\end{array}$ & $\begin{array}{l}\text { Significance } \\
\mathrm{p}\end{array}$ \\
\hline Vitamin D sterols & 67.3 & & 63.2 & & \\
\hline Calcitriol & 34.7 & $2.04 \pm 1.42$ & 34.7 & $2.13 \pm 1.44$ & n.s. \\
\hline Paricalcitol & 34.7 & $19.59 \pm 12.22$ & 26.5 & $13.00 \pm 9.97$ & n.s. \\
\hline Alfacalcidol & 2.0 & 7.0 & 2.0 & 1.75 & n.s. \\
\hline Pulse administration & 46.9 & & 29.3 & & $<0.05$ \\
\hline Continuous administration & 20.4 & & 41.3 & & $<0.05$ \\
\hline
\end{tabular}

Table 3. Use of phosphate binders

\begin{tabular}{|c|c|c|c|c|c|}
\hline Drug & $\begin{array}{l}\text { Treated patients } \\
\text { at baseline, } \%\end{array}$ & $\begin{array}{l}\text { Mean dose at } \\
\text { baseline } \\
\text { mg/day }\end{array}$ & $\begin{array}{l}\text { Treated patients after } \\
12 \text { months on } \\
\text { cinacalcet, } \%\end{array}$ & $\begin{array}{l}\text { Mean dose after } \\
12 \text { months on } \\
\text { cinacalcet, mg/day }\end{array}$ & $\begin{array}{l}\text { Significance } \\
\mathrm{p}\end{array}$ \\
\hline Phosphate binders & 87.8 & & 87.8 & & \\
\hline Calcium carbonate, tbl. $500 \mathrm{mg}$ & 44.9 & $2,450 \pm 1,050$ & 43.9 & $2,600 \pm 1,450$ & n.s. \\
\hline Sevelamer $\mathrm{HCl}$, tbl. $800 \mathrm{mg}$ & 61.2 & $4,240 \pm 1,520$ & 61.0 & $4,320 \pm 1,840$ & n.s. \\
\hline Lanthanum carbonate, tbl. $500 \mathrm{mg}$ & 2.0 & 1,500 & 12.2 & $2,100 \pm 630$ & n.s. \\
\hline Aluminium based & 0 & - & 0 & - & n.s. \\
\hline Combination of 2 binders & 18.4 & & 29.3 & & $<0.05$ \\
\hline
\end{tabular}

Table 4. Clinical complaints evaluated at the start of the study and after 6 and 12 months of cinacalcet treatment in 46 patients

\begin{tabular}{|c|c|c|c|c|c|c|}
\hline & $\begin{array}{l}\text { At the start } \\
\text { (month } 0 \text { ) }\end{array}$ & $\begin{array}{l}\text { After } 6 \text { months } \\
\text { (month 6) }\end{array}$ & $\begin{array}{l}\text { After } 12 \text { months } \\
\text { (month } 12 \text { ) }\end{array}$ & $\begin{array}{l}\text { Month } 0 \text { vs. } \\
\text { month } 6\end{array}$ & $\begin{array}{l}\text { Month } 6 \text { vs. } \\
\text { month } 12\end{array}$ & $\begin{array}{l}\text { Month } 0 \text { vs. } \\
\text { month } 12\end{array}$ \\
\hline Itching & $3.39 \pm 3.08$ & $1.91 \pm 2.07$ & $1.76 \pm 1.92$ & 0.000 & 1.000 & 0.006 \\
\hline Fatigue & $3.24 \pm 2.53$ & $2.59 \pm 2.15$ & $3.18 \pm 2.14$ & 0.000 & 0.010 & 0.250 \\
\hline Digestive problems & $0.74 \pm 1.69$ & $0.80 \pm 1.53$ & $1.13 \pm 1.67$ & 0.773 & 0.224 & 0.332 \\
\hline Bone pain & $3.35 \pm 3.31$ & $2.43 \pm 2.55$ & $2.20 \pm 2.49$ & 0.001 & 0.576 & 0.260 \\
\hline Muscle weakness & $3.40 \pm 3.22$ & $2.77 \pm 2.77$ & $3.05 \pm 2.55$ & 0.004 & 0.324 & 0.814 \\
\hline Total & $13.74 \pm 10.86$ & $10.09 \pm 8.53$ & $11.05 \pm 8.53$ & 0.000 & 0.159 & 0.326 \\
\hline
\end{tabular}

Muscle weakness was not evaluated in 3 locomotively challenged patients.

price of all administered drugs (cinacalcet, phosphate binders, and vitamin D and its analogs) was $228.10 \pm$ 249.45 CZK/day (approximately 8.77 \pm 9.59 EUR, using the conversion rate $1 \mathrm{EUR}=26.0 \mathrm{CZK}$ valid in August 2009) before the start of the cinacalcet treatment and rose significantly $(\mathrm{p}=0.000)$ to $536.11 \pm 239.59 \mathrm{CZK} /$ day $(20.62 \pm 9.22 \mathrm{EUR})$ in month 12 . The cost of the treatment rose from months 0 to 4 and remained stable afterwards.

Cinacalcet: Effectiveness, Cost, and

Concomitant Treatment Patterns

\section{Discussion}

\section{Profile of Patients Who Started Cinacalcet Treatment}

The average age of patients and the prevalence of diabetics in our study were lower than the average in the Czech Republic [14] (the lower incidence of SHPT in diabetic and elderly patients is well known [15]).

The intensity of hemodialysis treatment corresponded to the current practice in the country. A short dialysis and

Kidney Blood Press Res 2010;33:333-342 


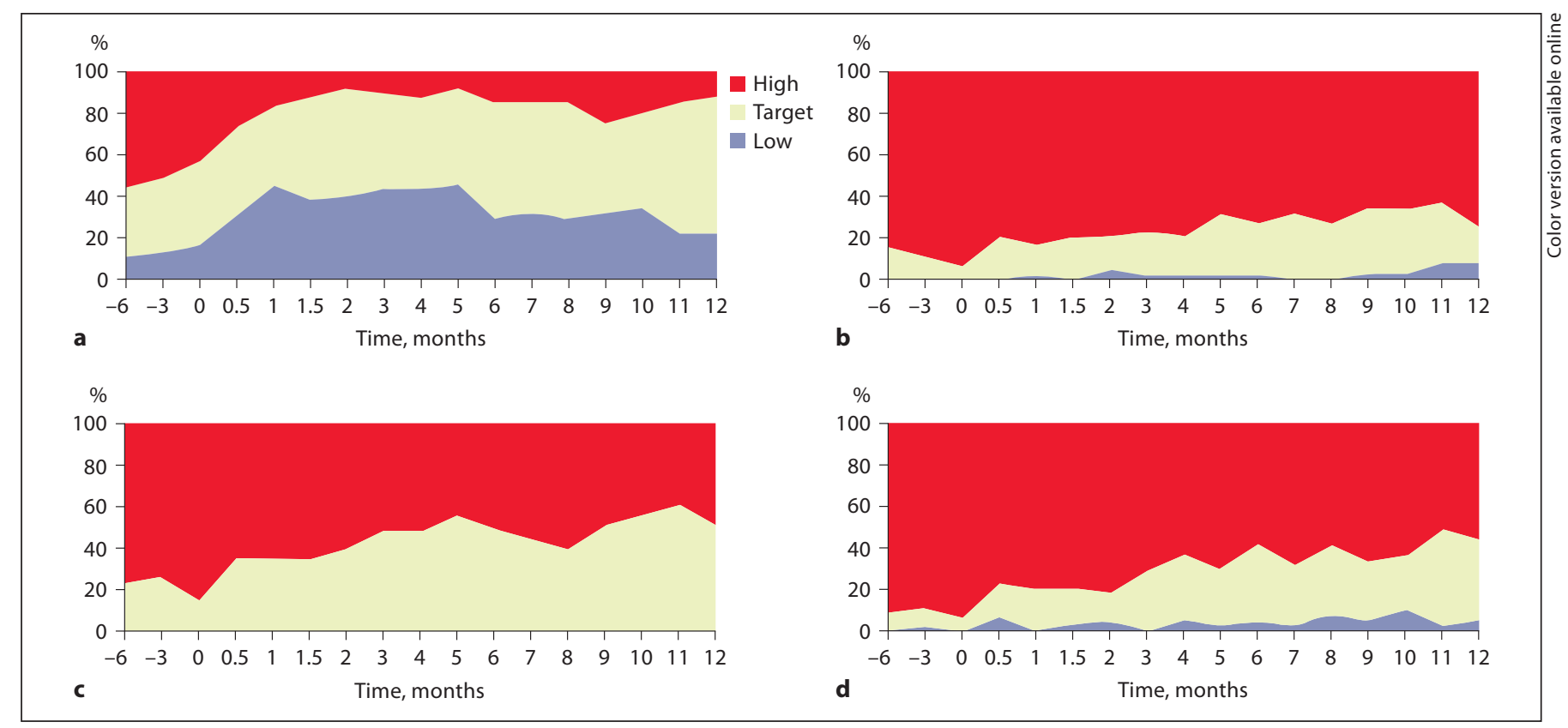

Fig. 3. Percentage of patients meeting the Kidney Disease Outcomes Quality Initiative (K/DOQI) recommended targets for serum calcium (a), phosphorus (b), calcium-phosphorus product (c), and iPTH (d). Month $0=$ Start of the cinacalcet treatment.

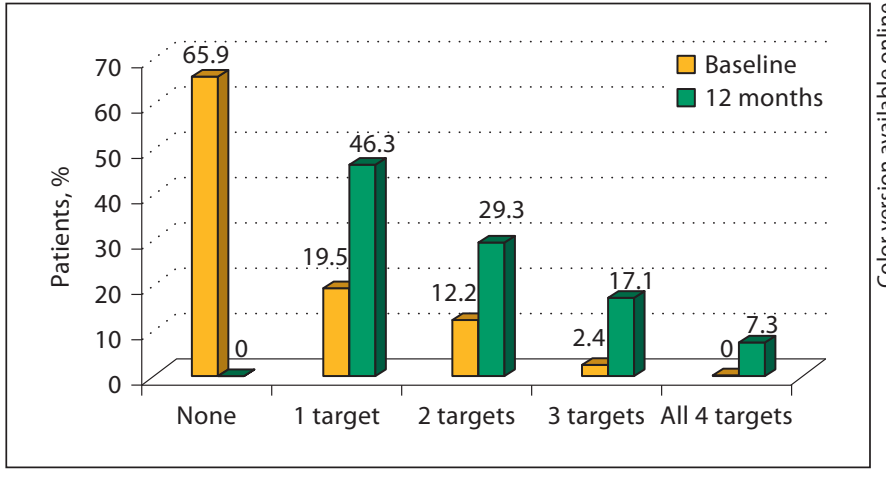

Fig. 4. Percentage of patients meeting a combination of Kidney Disease Outcomes Quality Initiative (K/DOQI) recommended targets at the start of the study and after 12 months of cinacalcet treatment.

a low number of dialysis sessions per week usually result in a positive phosphate balance, especially in patients with adequate protein intake. In $7.7 \%$ of patients the dialysis sessions were shorter than $4 \mathrm{~h}$ and $5.8 \%$ of patients had only 2 dialysis sessions a week. A more intense dialysis treatment might thus improve the rather poor phosphate control in our group of patients. Nevertheless, the dialysis adequacy, assessed by $\mathrm{Kt} / \mathrm{V}$ and urea reduction ratio, was satisfactory.
The percentage of patients with calcifications was strikingly low compared to other studies where the prevalence of calcifications in non-selected dialysis populations was usually as high as $60-80 \%$ [6]. The reason for this phenomenon might be the relatively low mean age of our group as well as the poor diagnostics of extra-osseal calcifications. Most of the nephrologists did not perform any calcification screening. Due to the observational character of the study, the nephrologists were not obliged to conduct any extra examinations, they did not screen the patients for extra-osseal calcifications and thus the calcifications may have remained undiagnosed.

As for the examination of the parathyroid glands, a surprisingly large number of patients (38.5\%) did not undergo any parathyroid gland examination during the 18-month period (starting 6 months before the commencement of the study until its end). Even in those with large parathyroid glands, parathyroidectomy was not considered.

\section{Cinacalcet Dose, Side Effects of the Treatment, and Concomitant Treatment of SHPT}

The mean dose of $44.1 \mathrm{mg} / \mathrm{d}$ in month 12 was lower than in other published studies, e.g. 52.0 and $62.3 \mathrm{mg}$ in the 4th and 9th months, respectively, in a Spanish study [16], $55 \mathrm{mg}$ [17], $57 \mathrm{mg}$ in the treated population in the 
ECHO study [18], and $55 \mathrm{mg}$ in a large study on a DaVita dialysis population [17]. It was much higher in studies with a strict dosing protocol, where it reached $107 \mathrm{mg}$ [19]. Insufficient up-titrating has already been described elsewhere $[17,18]$. Given the fact that the control of calcium-phosphate disturbances was not optimal, the reason for drug underdosing might be either its side effects, patients' refusal to take a higher dose, or the price of the drug that limits its prescribed amount (in the Czech Republic, medical insurance companies set a financial limit for prescription drugs and penalize healthcare providers for exceeding it).

Surprisingly, asymptomatic hypocalcemia was not reported as a side effect except for 1 case, and it was the cause of discontinuation in other 2 cases. Nonetheless, $32.6 \%$ of patient had $\mathrm{s}-\mathrm{Ca}$ of $<2.1 \mathrm{mmol} / \mathrm{l}$ in month 6 .

More than $2 / 3$ of the patients were taking active vitamin D or its analogs even though only 6.1 and $17.1 \%$ of the patients did not have hyperphosphatemia in months 0 and 12 , respectively. If the active vitamin $\mathrm{D}$ prescription recommendations had been strictly adhered to, only the patient without hyperphosphatemia (and hypercalcemia) would have been allowed to take it. This shows that nephrologists often do not adhere to the prescription recommendations in order to reduce the elevated iPTH levels. The use of vitamin D together with cinacalcet was much more common in the DaVita population where less than $8 \%$ of patients on cinacalcet were not treated with vitamin D [17].

As expected, we noticed a shift from the pulse to continuous vitamin $\mathrm{D}$ administration during the study.

The usage of phosphate binders was insufficient throughout the study. Phosphate binders have been employed in rather low doses compared to other studies [16, 17], and the use of a combination of 2 binders was rather rare -18.4 and $29.3 \%$ of patients in months 0 and 12 , respectively. Non-calcium-based phosphate binders were never combined together and were used in $73.2 \%$ of patients, whereas in the DaVita population, as much as $82 \%$ of the patients were receiving them and the dosage was higher by $31 \%$ for lanthanum carbonate and by $112 \%$ for sevelamer [17]. By contrast, calcium carbonate was used slightly more often in our group of patients and its mean dose was higher by $43 \%$ [17], probably for its low cost. $12.2 \%$ of the patients did not take any phosphate binder both in months 0 and 12 . The differences between the numbers of patients and the doses of phosphate binders used before and at the end of the study were not significant except for lanthanum carbonate, the usage of which increased probably because of its introduction to the
Czech market at the start of the study. To our surprise, there was no rise in the use of calcium carbonate, which could have helped to treat the hypocalcemia observed in $1 / 3$ of the patients in month 6 .

\section{Clinical and Laboratory Impact of Treatment}

As expected, we observed a statistically significant drop in s-Ca, s-P, Ca $\times$ P, and iPTH. The decreasing trend seems to be yet more important in the light of the fact that there was an increasing trend in s-P and $\mathrm{Ca} \times \mathrm{P}$ during the 6 months before the treatment (data not shown). When comparing our results with other studies, we have to point out that the initial mean iPTH of $919.0 \pm 465.6 \mathrm{pg} /$ $\mathrm{ml}$ (which dropped to $372.1 \pm 294.6 \mathrm{pg} / \mathrm{ml}$ ) in our group of patients was far higher that it was in other studies. For instance, Moe et al. [20] in their study indicate an iPTH of $590 \pm 39 \mathrm{pg} / \mathrm{ml}$ with a drop to $451 \pm 65 \mathrm{pg} / \mathrm{ml}$ after 100 weeks of treatment with no change in s-Ca $(2.42$ $\mathrm{mmol} / \mathrm{l}$ ) and a drop in s-P from 1.87 to $1.84 \mathrm{mmol} / \mathrm{l}$. In another study, the start iPTH of $426 \pm 274$ dropped to $300 \pm 228 \mathrm{pg} / \mathrm{ml}$, s-Ca reached the values of 2.37 and $2.20 \mathrm{mmol} / \mathrm{l}$, respectively, and s-P 2.00 and $1.78 \mathrm{mmol} / \mathrm{l}$, respectively [21]. In the recently published ECHO study, the mean iPTH was $721 \mathrm{pg} / \mathrm{ml}$ [18], and in the DaVita population, it reached $576.9 \pm 505.8 \mathrm{pmol} / 1$ [17]. This shows that our patients had more severe SHPT than the other treated groups of patients. This might be partly due to the reimbursement policy valid throughout the study where cinacalcet was only reimbursed in the patients with an iPTH of $>476 \mathrm{pg} / \mathrm{ml}$. The drop in s-Ca in our patients is comparable to or even higher than that in the other studies. The drop in s-P is comparable, but the levels of s-P are consistently higher. The reason for this might be either the insufficient usage of phosphate binders, or uncontrolled SHPT with $56.1 \%$ of patients with undesirably high iPTH levels after 12 months of treatment.

With regard to the clinical complaints, we observed just temporary alleviation of fatigue, bone pain, and muscle weakness in month 6 , as their intensity returned to the original values in month 12 . We have not found any comparable data elsewhere. Cinacalcet diminished the intensity of itching and this effect lasted until month 12 . The intensity of digestive disorders, which is a commonly described side effect of cinacalcet, was generally low.

\section{Percentage of Patients Meeting the K/DOQI Criteria} for Calcium-Phosphorus Metabolism

We decided to use the K/DOQI criteria to assess the effect of cinacalcet treatment as the study was designed 
in 2006 when the K/DOQI targets were most widely used in the Czech Republic. The percentage of patients meeting the K/DOQI criteria for calcium-phosphorus metabolism remained low even in month 12 . The main problem was the poor phosphatemia control with $75.6 \%$ of patients being still hyperphosphatemic in month 12 . According to the treatment analysis (see above), this might have been caused by the insufficient dosing of phosphate binders as well as a relatively low use of phosphate binder combinations rather than inadequate dialysis. $22 \%$ of patients were hypocalcemic in month 12 , which probably contributed to the high percentage of patients with persistent hyperparathyroidism. The cinacalcet underdosing and advanced SHPT with hypertrophic parathyroid glands (in at least $36.5 \%$ of patients) might have been another cause of insufficient hyperparathyroidism control as the initial as well as final levels of iPTH in the patients with hypertrophic parathyroid glands were significantly higher than the ones in the patients without a proven hypertrophic parathyroid gland (data not shown).

Only 7.3\% of patients met all the four K/DOQI criteria in month 12, whereas in a 9-month Spain study, this number was as high as $64.7 \%$ [16]. Here the s-P was in the target range in $71 \%$ of patients at the start and in $88 \%$ of patients at the end of the study. s-Ca was in the target range in 18 and $94 \%$ of the patients, respectively. Calcium-containing phosphate binders were used in $50 \%$ of patients, aluminium-based phosphate binders in $29 \%$, and sevelamer hydrochloride in $86 \%$. The last one was administered at doses of 11.4 tablets/day at the start and 7.2 tablets/day at the end of the study. Similarly, in the OPTIMA study, where conventional therapy with cinacalcet (in 368 patients) was compared with conventional therapy without cinacalcet, $77 \%$ of the patients on cinacalcet met the targets for iPTH and only $22 \%$ did so on conventional therapy without cinacalcet. The targets for $\mathrm{Ca} \times \mathrm{P}$ were met in 77 and $58 \%$ of patients, for s-Ca in 76 and $33 \%$, and for s-P in 63 and $50 \%$ of patients, respectively [22]. Our results turned out to be closer to those of an older 6-month study where the targets were met in $49 \%$ of the patients for s-Ca, in $46 \%$ for s-P, in $65 \%$ for $\mathrm{Ca} \times \mathrm{P}$, and in $41 \%$ of the patients for iPTH [19]; but here again, the phosphatemia control was superior to that in our study. In the recently published ECHO study reflecting real practice, the percentage of patients meeting the targets for $\mathrm{PPTH}$ and $\mathrm{Ca} \times \mathrm{P}$ was $18 \%$ [18], and in the large $\mathrm{DaVita}$ population, all the K/DOQI targets were met in $6.2 \%$ of the patients [17].
The increase in the proportion of patients achieving the K/DOQI targets proves pivotal when it comes to the association of the control of calcium-phosphate metabolism parameters and survival in dialysis patients [23].

\section{Comparison of Hospitalization Rates during and before Cinacalcet Treatment}

The hospitalization rate before and during cinacalcet treatment did not change significantly. The hospitalization rates were surprisingly low, $2-5$ times lower than in other large studies $[24,25]$. The reason for this might be that cinacalcet as an expensive drug was prescribed to a group of patients with fewer comorbidities. The low hospitalization rates and the low number of patients in our study might account for why we did not observe a drop in the cardiovascular hospitalization rate described elsewhere [25].

\section{Comparison of Direct Cost of Medical SHPT Therapy during and before Cinacalcet Treatment}

The total direct costs of medical SHPT therapy were significantly higher with cinacalcet. The same finding was reported by Arenas et al. [16], with a rise in direct monthly costs from 569.3 to 739.9 EUR (the calculated daily cost thus rose from 19 to 24.7 EUR), even with a reduction in daily vitamin $\mathrm{D}$ and phosphate binder doses. Our calculated daily costs are a bit lower, in all probability due to the lower cinacalcet and phosphate binders dosages. In the USA, the direct drug cost for treating SHPT in hemodialysis patients was USD 80.20/week for generic i.v. calcitriol and USD 278/week for cinacalcet [26].

Considering the high price of cinacalcet, Narayan et al. [27] recommend that cinacalcet be used in patients with short expected survival or those awaiting kidney transplant as it proves cost-effective only in patients who are to be dialyzed for less than $7.25 \pm 0.25$ months. In all other patients, parathyroidectomy is the most cost-effective treatment [27]. The cost-effectiveness of long-term cinacalcet treatment was questioned by Garside et al. [28] as well, who, nevertheless, used a high mean daily dose of $94 \mathrm{mg} /$ day for their analysis.

For pharmaco-economical assessment, it is vital to know the impact of cinacalcet on patients' morbidity and, more importantly, mortality. This is the goal of ongoing studies like EVOLVE - Evaluation of Cinacalcet $\mathrm{HCl}$ Therapy to Lower CV Events [29] or the ADVANCE study aiming to test coronary calcification progression in hemodialysis patients treated with cinacalcet and low doses of vitamin D. Retrospective analyses of the 3rd phase 
clinical studies show that cinacalcet added to standard SHPT treatment with phosphate binders and vitamin D lowers the need for parathyroidectomy by $93 \%$, the risk of fracture by $54 \%$, and the cardiovascular hospitalization risk by $39 \%$ [30].

\section{Conclusion}

Cinacalcet is a potent drug for the treatment of SHPT in dialysis patients, even in patients with advanced SHPT. Not only does it improve the patients' laboratory profile and raises the probability of meeting the K/DOQI recommended targets, it also relieves itching, and transiently alleviates fatigue, bone pain, and muscle weakness.

Phosphate binders administered in sufficient dosage and vitamin D sterols are still the cornerstones of the SHPT therapy even when cinacalcet is administered. Hyperphosphatemia and hypocalcemia during cinacalcet treatment still represent a challenge. Constant monitoring of the laboratory results achieved helps to tailor therapy. The high cost of cinacalcet should be considered chiefly when it is to be prescribed in the long run.

Our results indicate that, in the Czech Republic, the following issues should be attended to: (1) diagnostics of parathyroid adenoma; (2) diagnostics of extra-osseal calcifications; (3) low usage of higher doses of phosphate binders, usage of combination of binders, usage of aluminium-based binders; (4) underdosing of cinacalcet; (5) monitoring and treating hypocalcemia occurring during cinacalcet treatment; (6) parathyroidectomy in advanced SHPT, and (7) a change in reimbursement policy enabling the treatment of patients with less advanced SHPT.

In our group of patients, we identified the need to raise the doses of phosphate binders, monitoring and treating hypocalcemia, and the need for adequate doses of cinacalcet. In some patients with advanced SHPT, parathyroidectomy instead of cinacalcet treatment should be considered.

\section{Acknowledgments}

We would like to thank all MMM investigators: Petr Buček, $\mathrm{MD}$, Olga Herůfková, MD, Kateřina Heřmanová, MD, Aleš Hrubý, MD, Vít Kašpárek, MD, Jan Kubánek, MD, Januš Kubatko, MD, Mojmír Lanžhotský, MD, Patrik Letocha, MD, Marie Marsová, MD, MBA, Zuzana Nemcová, MD, Roman Ondraschek, MD, Robert Rakowski, MD, Sylvie Schwarzová, MD, Jitka Slivková, MD, Jiří Synek, MD, Milouš Vyskočil, MD, and Petr Vězda, MD. We would also like to thank Martin Dvořák, Mgr., $\mathrm{PhD}$ for his assistance with the data collection.

Tomáš Urbánek, assist. prof., $\mathrm{PhD}$ was supported by the research plan of the Institute of Psychology, Academy of Sciences of the Czech Republic (No. AV0Z70250504).

\section{References}

1 Cannata-Andía J, Carrera F: The pathophysiology of secondary hyperparathyroidism and the consequences of uncontrolled mineral metabolism in chronic kidney disease: the role of COSMOS. NDT Plus 2008; 1(suppl 1):i2-i6.

2 Smržová J: Hyperphosphatemia - a serious complication of chronic renal insufficiency and end-stage renal disease. 1st part - etiopathogenesis, consequences, and diagnostics (in Czech). Vnitr Lek 2005;51:327-335.

3 Block GA, Klassen PS, Lazarus JM: Mineral metabolism, mortality, and morbidity in maintenance hemodialysis. J Am Soc Nephrol 2004;15:2208-2218.

4 Ganesh SK, Stack AG, Lewin NW et al: Association of elevated serum $\mathrm{PO}(4), \mathrm{Ca} \times$ $\mathrm{PO}(4)$ product, and parathyroid hormone with cardiac mortality risk in chronic hemodialysis patients. J Am Soc Nephrol 2001;12: 2131-2138.
5 Moe SM, Drueke TB: Management of secondary hyperparathyroidism - the importance and the challenge of controlling parathyroid hormone levels without elevating calcium, phosphorus, and calcium-phosphorus product. Am J Nephrol 2003;23:369-379.

6 Olgaard K (ed): Clinical Guide to Bone and Mineral Metabolism in CKD. New York, National Kidney Foundation, 2006.

7 Nemeth EF, Steffey ME, Hammerland LG, et al: Calcimimetics with potent and selective activity on the parathyroid calcium receptor. Proc Natl Acad Sci USA 1998;95:4040-4045.

8 Frazão J, Rodriguez M: Secondary hyperparathyroidism disease stabilization following calcimimetic therapy. NDT Plus 2008; 1(suppl 1):i12-i17.

9 National Kidney Foundation: K/DOQI clinical practice guidelines for bone metabolism and disease in chronic kidney disease. Am J Kidney Dis 2003;42(suppl 3):1-201.

$\checkmark 10$ Block GA, Martin KJ, de Francisco AJ, et al: Cinacalcet for secondary hyperparathyroidism in patients receiving hemodialysis. $\mathrm{N}$ Engl J Med 2004;350:1516-1525.
11 Lindberg JS, Culleton B, Wong G, et al: Cinacalcet $\mathrm{HCl}$, an oral calcimimetic agent for the treatment of secondary hyperparathyroidism in hemodialysis and peritoneal dialysis: a randomized, double-blind, multicenter study. J am Soc Nephrol 2005;16:800-807.

12 Meola M, Petrucci I, Barsotti G: Long-term cinacalcet treatment and conventional therapy reduces parathyroid hyperplasia in severe secondary hyperparathyroidism. Nephrol Dial Transplant 2009;24:982-989.

13 Riccardi D, Martin D: The role of calciumsensing receptor in the pathophysiology of secondary hyperparathyroidism. NDT Plus 2008;1(suppl 1):i7-i11.

14 Rychlík I, Lopot F: Statistical yearly report on dialysis treatment in the Czech Republic in 2008 (in Czech). http://www.nefrol.cz/index.php?\&desktop $=$ clanky\&action $=$ view\& id $=500$. Accessed on November 6, 2009.

15 Couttenye MM, D'Haese PC, Verschoren WJ, et al: Low bone turnover in patients with renal failure. Kidney Int 1999;56(suppl 73):S70-S76. 
-16 Arenas MD, Alvarez-Ude F, Gil MT, et al: Implementation of 'K/DOQI Clinical Practice Guidelines for Bone Metabolism and Disease in Chronic Kidney Disease' after the introduction of cinacalcet in a population of patients on chronic haemodialysis. Nephrol Dial Transplant 2007;22:1639-1644.

-17 St Peter WL, Li Q, Lie J, et al: Cinacalcet use pattern and effects on laboratory values and other medications in a large dialysis organization, 2004 through 2006. Clin J Am Soc Nephrol 2009;4:354-360.

18 Ureña P, Jacobson SH, Zitt E, et al: Cinacalcet and achievement of the NKF/K-DOQI recommended target values for bone and mineral metabolism in real-world clinical practice - the ECHO observational study. Nephrol Dial Transplant 2009;24:28522859.

-19 Moe SM, Chertow GM, Coburn JW, et al: Achieving NKF-K/DOQI bone metabolism and disease treatment goals with cinacalcet HCl. Kidney Int 2005;67:760-771.

-20 Moe SM, Cunningham J, Bommer J, et al: Long-term treatment of secondary hyperparathyroidism with the calcimimetic cinacalcet HCl. Nephrol Dial Transplant 2005; 20:2186-2193.
21 Lazar E, Herbert K, Poma T, Stankus N: Long-term outcomes of cinacalcet and paricalcitol titration protocol for treatment of secondary hyperparathyroidism. Am J Nephrol 2007;27:274-278.

22 Messa P, Macário F, Yaqoob M, et al: The OPTIMA study: assessing a new cinacalcet (Sensipar/Mimpara) treatment algorithm for secondary hyperparathyroidism. Clin J Am Soc Nephrol 2008;3:36-45

23 Danese MD, Belozeroff V, Smirnakis G, et al: Consistent control of mineral and bone disorder in incident hemodialysis patients. Clin J Am Soc Nephrol 2008;3:1423-1429.

24 Mix TC, St Peter WL, Ebben J, et al: Hospitalization during advancing chronic kidney disease. Am J Kidney Dis 2003;42:972-981.

25 Cunningham J, Danese M, Olson K, Klassen P, Chertow GM: Effects of the calcimimetic cinacalcet $\mathrm{HCl}$ on cardiovascular disease fracture, and health-related quality of life in secondary hyperparathyroidism. Kidney Int 2005;67:467-476.
26 Joy MS, Karagiannis PC, Peyerl FW: Outcomes of secondary hyperparathyroidism in chronic kidney disease and the direct cost of treatment. J Manag Care Pharm 2007;13: 397-411.

27 Narayan R, Perkins RM, Berbano EP, et al: Parathyroidectomy versus cinacalcet hydrochloride-based medical therapy in the management of hyperparathyroidism in ESRD: a cost utility analysis. Am J Kidney Dis 2007; 49:801-813

28 Garside R, Pitt M, Anderson R, et al: The effectiveness and cost-effectiveness of cinacalcet for secondary hyperparathyroidism in end-stage renal disease patients on dialysis: a systematic review and economic evaluation. Health Technol Assess 2007;11:1-167.

29 Chertow GM, Pupim LB, Block GA, et al: Evaluation of Cinacalcet Therapy to Lower Cardiovascular Events (EVOLVE): rationale and design overview. Clin J Am Soc Nephrol 2007;2:898-905.

30 Cunningham J, Floege J, London G, et al: Clinical outcomes in secondary hyperparathyroidism and the potential role of calcimimetics. NDT Plus 2008;1(suppl 1):i29-i35. 